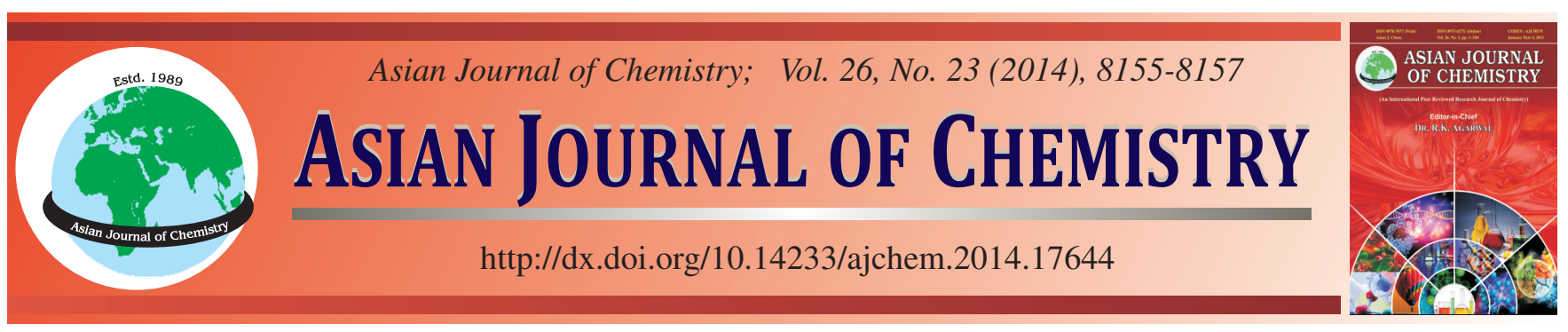

\title{
Large-Scale Synthesis of $(E)$-4-Amino-2-Methylbut-2-en-1-ol: Key Building Block for the Synthesis of trans-Zeatin
}

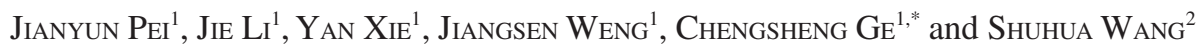

\begin{abstract}
${ }^{1}$ College of Chemical and Material Engineering, Quzhou University, Quzhou 324000, P.R. China
\end{abstract}
${ }^{2}$ Technology Center of Zhejiang Juhua Group, Quzhou 324004, P.R. China

*Corresponding author: Tel/Fax: +86 570 8015339; E-mail: gechengsheng@qzu.zj.cn

\section{INTRODUCTION}

(E)-4-Amino-2-methylbut-2-en-1-ol is the structural unit of natural products such as Cytokinins trans-zeatin ${ }^{1,2}$ and 9(2-deoxy- $\beta$-D-ribofuran-osyl)-trans-zeatin ${ }^{3}$. Isolated from immature sweet corn (Zea mayes) kernels, trans-zeatin shows as the most active cytokinin. To our best of knowledge, transzeatin is currently an expensive commercial cytokinin in the market, which is attributed to the difficulty of affording key building block $(E)$-4-amino-2-methylbut-2-en-1-ol on industrial scale. Although numerous procedures for the synthesis of (E)-4-amino-2-methylbut-2-en-1-ol have been reported ${ }^{4-13}$, those experimental procedures are not suitable for scale-up. Additionally, toxic or expensive reagents were involved in those protocols. Jordis et al. ${ }^{14}$ reported an optimized synthesis of some $\gamma, \gamma$-disubstituted allylamine, however raw material is expensive and not suitable for commercial purpose. We herein report a practical large-scale synthesis of (E)-4-amino-2methylbut-2-en-1-ol and with this key intermediate, transzeatin could be accessed on industrial scale.

\section{EXPERIMENTAL}

Solvents and reagents were obtained from commercial sources without further purification. ${ }^{1} \mathrm{H}$ and ${ }^{13} \mathrm{C}$ NMR spectra were recorded on a Varian $400-\mathrm{MHz}$ spectrometer using $\mathrm{CDCl}_{3}$ or $\mathrm{DMSO}_{-} \mathrm{D}_{6}$ as solvent. Melting points were determined on WRS-2 melting-point apparatus (Shanghai, China) and uncorrected.

Synthesis of 1-[(E)-4-bromo-3-methyl-2-butenyl]-1azonia-3,5,7-triaza-tricyclo [3.3.1.1] decane bromide (2): To a solution of (E)-1,4-dibromo-2-methylbut-2-ene (1) (4 kg,
$17.5 \mathrm{~mol})$ in dichloromethane ( $32 \mathrm{~L}$ ) was added hexamethylenetetramine $(2.46 \mathrm{~kg}, 17.5 \mathrm{~mol})$ at $0{ }^{\circ} \mathrm{C}$, and the mixture was allowed to warm to room temperature. It was stirred overnight and filtered. The obtained white solid was dried to give $\mathbf{2}$ (5.22 $\mathrm{kg}, 92 \%$ yield). It was directly applied to next step.

Synthesis of (E)-tert-butyl 4-hydroxy-3-methylbut-2enylcarbamate (4): To a solution of $2(4 \mathrm{~kg}, 12.4 \mathrm{~mol})$ in methanol $(10 \mathrm{~L})$ was added concentrated hydrochloric acid (6 L, $29 \mathrm{~mol}$ ) carefully, and the mixture was heated to reflux for $2 \mathrm{~h}$. The resulting solution was cooled down to $0{ }^{\circ} \mathrm{C}$, and then filtered. The filtrate was concentrated to half of its volume, cooled down to $0{ }^{\circ} \mathrm{C}$ again and filtered. The filtrate was concentrated to dryness to give $3 \mathrm{~kg}$ of $\mathbf{3}$ as a colourless oil.

To a solution of sodium carbonate $(4.82 \mathrm{~kg}, 37.2 \mathrm{~mol})$ and Boc anhydride $(2.7 \mathrm{~kg}, 12.4 \mathrm{~mol})$ in ethyl acetate $(16 \mathrm{~L})$ and water (24 L) was added dropwise the above obtained 3 (3 $\mathrm{kg}$ ) in ethyl acetate $(4 \mathrm{~L})$ at $0{ }^{\circ} \mathrm{C}$, and then the mixture was allowed to warm to room temperature. It was stirred overnight and the water phase was extracted with ethyl acetate. Combined organic phase was washed with brine and dried over $\mathrm{Na}_{2} \mathrm{SO}_{4}$. It was evaporated to give $2.7 \mathrm{~kg}$ of $\mathrm{N}$-Boc protected derivative of $\mathbf{3}$ as a colorless oil.

To a solution of the above obtained colorless oil in $95 \%$ ethanol $(15 \mathrm{~L})$ was added sodium acetate $(1.52 \mathrm{~kg}, 18.6 \mathrm{~mol})$, and the reaction mixture was refluxed for $4 \mathrm{~h}$. The resulting solution was cooled down to room temperature and $20 \%$ aqueous solution of sodium hydroxide (34 L, $19.6 \mathrm{~mol}$ ) was added into the reaction mixture, which was refluxed for $2 \mathrm{~h}$, and then evaporated. The resulting residue was layered with ethyl acetate $(10 \mathrm{~L})$ and water $(10 \mathrm{~L})$, and water phase was extracted with ethyl acetate $(3 \times 10 \mathrm{~L})$. The combined organic 
phase was washed with saturated solution of sodium bicarbonate and brine, dried over $\mathrm{Na}_{2} \mathrm{SO}_{4}$. The filtrate was concentrated to give $2.5 \mathrm{~kg}$ of $4 .{ }^{1} \mathrm{H}$ NMR $\left(400 \mathrm{MHz}, \mathrm{CDCl}_{3}\right) \delta: 1.41(\mathrm{~s}, 9 \mathrm{H})$, 1.66 (s, 3H), 3.70-3.76 (m, 2H), 3.97 (s, 2H), 5.43 (t, $J=8 \mathrm{~Hz}$, 1H). ${ }^{1} \mathrm{H}$ NMR spectral data were consistent with described 9 .

Synthesis of $(\boldsymbol{E})$-4-amino-2-methylbut-2-en-1-ol (5): To a solution of $2.5 \mathrm{~kg}$ of $\mathbf{4}$ in dichloromethane (3.5 L) was added trifluoroacetic acid $(1.4 \mathrm{~kg}, 12.4 \mathrm{~mol})$. The mixture was stirred for $2 \mathrm{~h}$ and then neutralized with sodium hydroxide, concentrated. The residue was distilled over high vaccum $(0.01 \mathrm{mmHg})$ at $60{ }^{\circ} \mathrm{C}$ to give $751 \mathrm{~g}$ of 5 as a colourless oil in $60 \%$ yield. ${ }^{1} \mathrm{H}$ $\mathrm{NMR}\left(400 \mathrm{MHz}, \mathrm{CDCl}_{3}\right) \delta: 1.63(\mathrm{~s}, 3 \mathrm{H}), 3.30$ (t, $\left.J=8 \mathrm{~Hz}, 2 \mathrm{H}\right)$, $3.95(\mathrm{~s}, 2 \mathrm{H}), 5.49(\mathrm{t}, J=8 \mathrm{~Hz}, 1 \mathrm{H}) .{ }^{1} \mathrm{H}$ NMR spectral data were consistent with described ${ }^{7}$.

Synthesis of trans-zeatin: To a solution of 6-chloropurine $(656 \mathrm{~g}, 4.25 \mathrm{~mol})$ and triethylamine $(516 \mathrm{~g}, 5.1 \mathrm{~mol})$ in butyl alcohol $(1.8 \mathrm{~L})$ was added 5 (430 g, $4.25 \mathrm{~mol})$. The reaction mixture was heated to reflux for $4 \mathrm{~h}$, and cooled down to room temperature slowly. The solvent was evaporated and the residue was twice recrystallized with water and ethanol to give $661 \mathrm{~g}$ of trans-zeatine as a white solid in $71 \%$ yield with $99 \%$ HPLC purity. m.p. $208-209{ }^{\circ} \mathrm{C} .{ }^{1} \mathrm{H}$ NMR $\left(400 \mathrm{MHz}\right.$, DMSO- $\left.d_{6}\right) \delta$ : 1.64 (s, 3H), 3.33 (s, 2H), 4.09 (br, 1H), 4.73 (br, 1H), 5.51 (t, $J=8 \mathrm{~Hz}, 1 \mathrm{H}), 7.70$ (br, 1H), 8.06 (s, 1H), 8.16 (s, 1H), 12.84 (br, $1 \mathrm{H}) .{ }^{1} \mathrm{H}$ NMR spectral data were consistent with described ${ }^{7}$.

\section{RESULTS AND DISCUSSION}

Recently Madhusudhan et al. ${ }^{15}$ discovered that hexamethylenetetramine, a bulky amine, could be applied to largescale synthesis of (Z)-4-chlorobut-2-en-1-amine hydrochloride starting from (Z)-1,4-dichlorobut-2-ene. The substitution of (Z)-1,4-dichlorobut-2-ene with hexamethylenetetramine in dichloromethane under refluxing gave mono-amination salt in nearly quantitative yield, and the formed salt has very low solubility in reaction solvent, which prevented the further substitution. Different from (Z)-1,4-dichlorobut-2-ene, $(E)$-1,4dibromo-2-methylbut-2-ene has more reactive bromide group and methyl group marks $E$-1,4-dibromo-2-methylbut-2-ene as an un-symmetric unit, which results in regio-selective amination involved. Initially, we refluxed (E)-1,4-dibromo-2methylbut-2-ene and hexamethylenetetramine in dichloromethane (Scheme-I). Unfortunately, we obtained a complex mixture. Further, the reaction mixture was stirred at ambient temperature. A white solid 2 was obtained in $92 \%$ yield. Further solvent optimization such as chloroform ( $85 \%$ yield), toluene (60\% yield) and dichloroethane (80\% yield) was explored. Thus far, dichloromethane gave best yield. Interestingly, we only obtained one isomer $\mathbf{2}$, and another isomer 2' was not detected.



Scheme-I: Regioselective amination via $\mathbf{1}$ and hexamethylenetetramine

Using delepine reaction condition compound 2 was converted to compound $\mathbf{3}$, which was subjected to $\mathrm{N}$-Bocprotection, subsequent acetoxylation and hydroxylation to give compound 4. De-protection of compound 4 with trifluoroacetic acid and distillation under vacuum gave $(E)$-4-amino-2methylbut-2-en-1-ol (5) in $60 \%$ overall yield (Scheme-II).
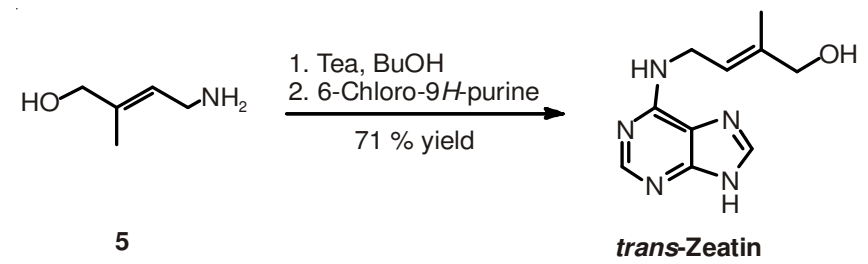

trans-Zeatin

Scheme-III: scale-up synthesis of trans-zeatin

Furthermore, $(E)$-4-amino-2-methylbut-2-en-1-ol (5) was coupled with 6-chloropurine to give $>99 \%$ purity of transzeatin in $71 \%$ yield after twice recrystallization (SchemeIII).

Eventually, trans-zeatin was prepared in $39 \%$ overall yield starting from trans-1,4-dibromo-2-methylbut-2-ene and hexamethylenetetramine.

In conclusion, we developed an efficient large-scale preparative method for (E)-4-hydroxy-3-methylbut-2-enyl. trans-Zeatin could be accessed on industrial scale, based on readily available starting material, operational simplicity and good yield.

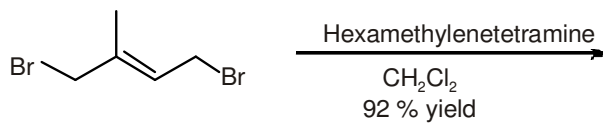

1

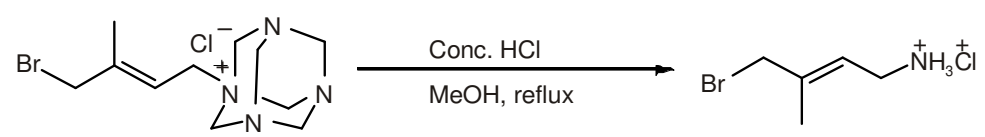

3

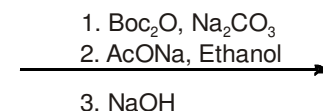

3. $\mathrm{NaOH}$

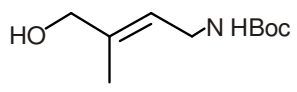



Scheme-II: Large-scale synthetic route of (E)-4-amino-2-methylbut-2-en-1-ol 


\section{ACKNOWLEDGEMENTS}

This research work was financially supported by Foundation of Provincial Education Department of Zhejiang of P.R. China (Grant No. Y201224719) and National Natural Science Foundation of China (No. 21472110).

\section{REFERENCES}

1. D.S. Letham, Life Sci., 2, 152 (1963).

2. M. Haidoune, I. Raynaud, N. O'Connor, P. Richomme, R. Mornet and M. Laloue, J. Agric. Food Chem., 46, 1577 (1998).

3. S.C. Chen and J.M. Mactaggart, U.S. Patent 4361702 (1980).

4. G. Shaw, B.M. Smallwood and D.V. Wilson, J. Chem. Soc., 921 (1966).

5. D.S. Letham and H. Young, Phytochemistry, 10, 2077 (1971).
6. D.S. Letham, R.E. Mitchell, T. Cebalo and D.W. Stanton, Aust. J. Chem., 22, 205 (1969).

7. C.C. Duke, J.K. Macleod, R.L. Summons, D.S. Letham and C.W. Parker, Aust. J. Chem., 31, 1291 (1978).

8. S. D. Robert, U.S. Patent 3960923 (1973)

9. S.A. Dibiase and G.W. Gokel, Synthesis, 629 (1977).

10. D.A. Powell and R.A. Batey, Org. Lett., 4, 2913 (2002).

11. M. Ohsugi, I. Ichimoto and H. Ueda, Agric. Biol. Chem., 38, 1925 (1974).

12. R. Mornet and L. Gouin, Tetrahedron Lett., 18, 167 (1977).

13. G. Desvages, Bull. Chim. Fr., 3329 (1969).

14. U. Jordis, G. Franz and K. Bernhard, Org. Prep. Proced. Int., 29, 529 (2009).

15. T. Rajesh, S.A. Azeez, E. Naresh, G. Madhusudhan and K. Mukkanti, Org. Process Res. Dev., 13, 638 (2009). 